\title{
Application of quinoxaline based diimidazolium salt in palladium catalyzed cross-coupling reactions
}

\author{
MUJAHUDDIN M SIDDIQUI, MOHAMMED WAHEED, SAJAD A BHAT \\ and MARAVANJI S BALAKRISHNA* \\ Phosphorus Laboratory, Department of Chemistry, Indian Institute of Technology Bombay, \\ Powai, Mumbai 400 076, India \\ e-mail: krishna@chem.iitb.ac.in
}

MS received 01 November 2014; revised 22 January 2015; accepted 24 January 2015

\begin{abstract}
The reaction of 2,3-bis(bromomethyl)quinoxaline with imidazole afforded the quinoxaline bridged diimidazolium salt (1) in good yield. Diimidazolium salt (1) in conjunction with $\mathrm{Pd}(\mathrm{OAc})_{2}$ was employed as a catalyst for $\mathrm{C}-\mathrm{C}$ cross-coupling reactions. The diimidazolium salt was found to be efficient in catalyzing Suzuki-Miyaura cross-coupling reaction in ethanol under ambient conditions. Moderate to good selectivity of the trans product was observed in the Heck cross-coupling reaction. The molecular structure of $\mathbf{1}$ was confirmed by single crystal X-ray diffraction study.
\end{abstract}

Keywords. Carbene; Imidazolium salt; Suzuki-Miyaura coupling; Mizoroki-Heck coupling; Palladium (II).

\section{Introduction}

Transition metal catalyzed cross-coupling reactions have emerged as the most efficient and versatile methods in academic research as well as in industry for the synthesis of natural products, pharmaceutical drugs, fine chemicals and advanced materials. ${ }^{1}$ Palladium catalyzed SuzukiMiyaura and Mizoroki-Heck are the most powerful $\mathrm{C}-\mathrm{C}$ bond formation reactions available to synthetic chemists due to the broad tolerance of functional groups and relatively mild reaction conditions. ${ }^{2}$ Apart from the well-known $\left[\mathrm{Pd}\left(\mathrm{PPh}_{3}\right)_{4}\right]$ as a catalyst, a vast number of palladium complexes containing bulky as well as electron rich phosphines have been designed and successfully employed in different cross-coupling reactions. ${ }^{3}$ However, phosphine-based auxiliary catalysts are expensive, toxic, necessitate a tedious method to prepare and require inert atmosphere and often mild reaction conditions. For a catalyst to be attractive or popular in the industrial sector, the ligands have to be cheaper, stable to moisture, readily available or involve simple methods of preparation. In this context, several phosphine-free catalytic systems with nitrogen as donor ligands such as amines, ${ }^{4 \mathrm{a}}$ imines $^{4 \mathrm{~b}}$ and oxazolines ${ }^{4 \mathrm{c}}$ as well as $\mathrm{NHCs}^{4 \mathrm{~d}-\mathrm{h}}$ have been designed and employed in various catalytic reactions.

Similar to phosphines, functionalized NHCs are becoming popular in recent years. ${ }^{5,6} \mathrm{NHC}$ ligands having

\footnotetext{
*For correspondence
}

extra donor sites or pendant donor arms: for example, tridentate pincer ligand with two carbene arms (I), hybrid pincer ligands with amine (II) or phosphine (III) donor $\mathrm{arms}^{7}$ or heteroatom functionalized dicarbene ligands with aromatic heterocyclic bridging units have been documented in the literature (chart 1). ${ }^{8}$ The strong $\sigma$-donor ability of NHC ligands in comparison with phosphines results in stronger metal-ligand bonding, thereby stabilizing the metal centre during the catalytic process by neutralizing the charge deficit at the metal centre. ${ }^{9,10}$ The dicarbene ligands of the type (IV) lead to dinuclear complexes with metal centres located in close proximity. Contrary to this, the dicarbene ligands of the type (V) places the metal centres in remote positions which can be seen as the dinuclear version of the picoline or benzoimidazoline functionalized carbene complexes (VI). ${ }^{11}$ As a part of our continuous efforts towards designing novel and cheap catalysts for cross-coupling reactions, ${ }^{12 \mathrm{a}-\mathrm{e}}$ we recently reported the diamino-diol based palladium catalysts for Suzuki-Miyaura cross coupling reaction. ${ }^{12 \mathrm{f}}$ Herein, we describe the synthesis of quinoxaline bridged imidazolium salt and its in situ generated palladium catalyst in Suzuki-Miyaura and Mizoroki-Heck coupling reactions.

\section{Experimental}

1-methyl Imidazole, bromo compounds, phenyl boronic acid and styrene were purchased from Aldrich. Anhydrous $\mathrm{K}_{2} \mathrm{CO}_{3}$ was purchased from S.D. Fine chemicals, 
and used as received without further purification. All other reagents were used as received. The ${ }^{1} \mathrm{H}$ and ${ }^{13} \mathrm{C}$ NMR spectra were taken in DMSO- $d_{6}$ with reference to TMS. GC analyses were conducted using an Agilent Gas Chromatograph 6890 Series, Hewlett Packard equipped with an HP5-MS capillary column $(30 \mathrm{~m} \times 0.25 \mathrm{~mm} \times$ $0.25 \mu \mathrm{m})$ and an FID detector. All GCMS analyses were done by Agilent 7890A GC system connected with 5975C inert XL EI/CI MSD (with triple axis detector).

\subsection{Synthesis of 2,3-bis(imidazolylmethyl)quinoxalium bromide (1)}

A mixture of 1-methyl imidazole $(0.26 \mathrm{~g}, 3.11 \mathrm{mmol})$ and 2,3-bis(bromomethyl)quinoxaline $(0.5 \mathrm{~g}, 1.58 \mathrm{mmol})$ in acetonitrile was refluxed over night at $80^{\circ} \mathrm{C}$. The solution was filtered under reduced pressure to obtain a brown precipitate, which was washed with petroleum ether and the residue obtained was recrystallized from ethanol to give colourless crystals of 1. Yield: $75 \%$. M.p.: $265-268^{\circ} \mathrm{C}$ (dec). IR (KBr) $v_{\max }\left(\mathrm{cm}^{-1}\right): 3408,3046,1567,1174$,
860, 776. ${ }^{1} \mathrm{H}-\mathrm{NMR}\left(400 \mathrm{MHz}, \mathrm{DMSO}-d_{6}\right): \delta 4.0$ (s, 6H, $\left.\mathrm{CH}_{3}\right), 6.17$ (s, 4H, $\left.\mathrm{CH}_{2}\right), 7.85-7.87$ (m, 4H, Ar), 7.92$7.95(\mathrm{~m}, 4 \mathrm{H}, A r), 9.42(\mathrm{~s}, 2 \mathrm{H}, \mathrm{NC} H \mathrm{~N}) .{ }^{13} \mathrm{C}-\mathrm{NMR}(400$ $\mathrm{MHz}, \mathrm{DMSO}-d_{6}$ ): $\delta 36.03$ (imidazolium- $\mathrm{NCH}_{3}$ ), 50.39 (quinoxaline- $\mathrm{CH}_{2} \mathrm{~N}$ ), 123.54, 123.71 (imidazolium- $C$ ), 128.50, 130.91 (quinoxaline- $C$ ), 137.94 (imidazolium$\mathrm{N} C \mathrm{~N}$ ), 140.08, 147.93 (quinoxaline- $C$ ). ESI-MS: $m / z$ $399.0954[\mathrm{M}-\mathrm{Br}]^{+}$.

\subsection{General method for Suzuki cross-coupling reaction}

In a two-neck round-bottomv flask, a mixture of palladium acetate $(1 \mathrm{~mol} \%), \mathbf{1}(1 \mathrm{~mol} \%), \mathrm{K}_{2} \mathrm{CO}_{3}(1 \mathrm{mmol})$, aryl bromide $(0.5 \mathrm{mmol})$, and phenyl boronic acid $(0.75 \mathrm{mmol})$ were allowed to reflux in ethanol at $78^{\circ} \mathrm{C}$. The course of reaction was monitored by GC analysis. Ethanol was removed under reduced pressure and the residue was dissolved in dichloromethane and passed through celite. An aliquot was taken with a syringe and subjected to GC analysis. Yields were calculated with aryl halides as internal standards.<smiles></smiles>

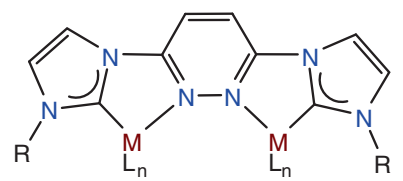

IV<smiles>[X][M]C1CN(Cc2ccccc2)CC1Cc1ccccc1</smiles>

II

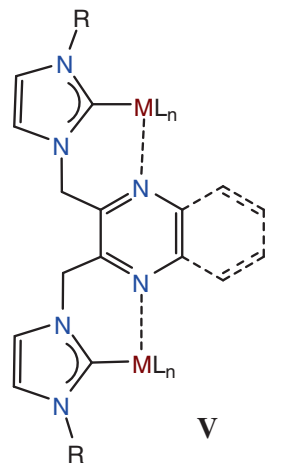<smiles></smiles>

III<smiles></smiles>

VI

Chart 1. Different coordination modes.

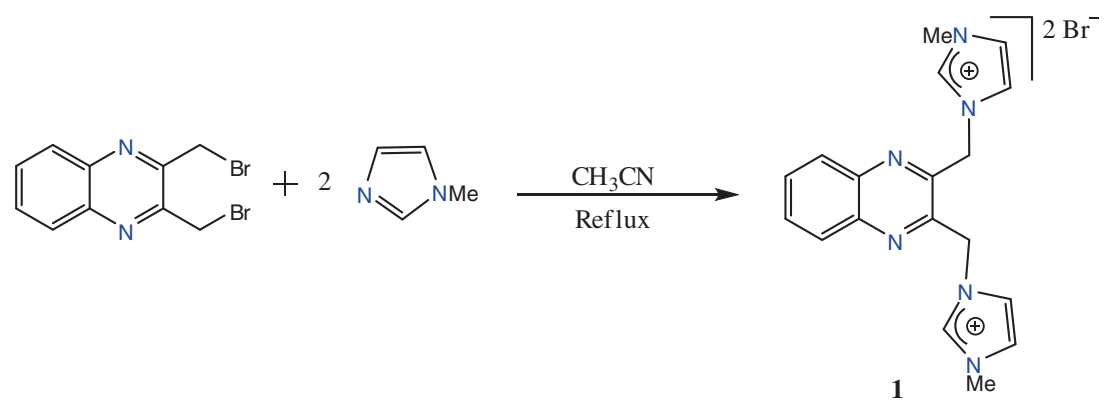

Scheme 1. Preparation of 2,3-bis(imidazolylmethyl)quinoxalium bromide (1). 


\subsection{General method for Heck cross-coupling reaction}

Heck coupling reactions were carried out using aryl bromides $(1.0 \mathrm{mmol})$, styrene $(1.4 \mathrm{mmol})$, and $\mathrm{K}_{2} \mathrm{CO}_{3}$ as base ( $2 \mathrm{mmol}$ ) dissolved in $5 \mathrm{~mL}$ of $\mathrm{N}, \mathrm{N}$-dimethylformamide (DMF). An appropriate amount of $1(1.0 \mathrm{~mol} \%)$ and palladium acetate $(2.0 \mathrm{~mol} \%)$ were added to this reaction mixture. The reaction mixture was heated to $130^{\circ} \mathrm{C}$ for the selected reaction time. Coupling product yields were calculated from $\mathrm{GC}$ data relative to the residual aryl halide. The product identity was confirmed by GC-MS.

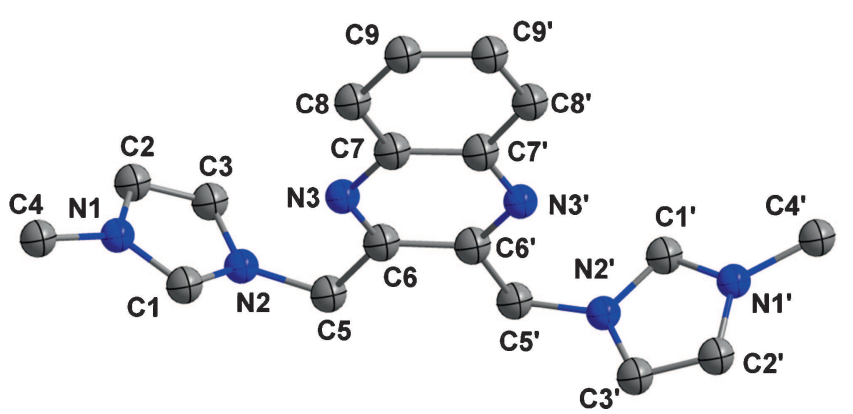

Figure 1. Molecular structure of 2,3 bis-(imidazolylmethyl) quinoxilium bromide (1). Hydrogen atoms and the bromide counterions have been omitted for clarity; thermal ellipsoids are drawn at $50 \%$ probability level. Selected bond angles $(\AA)$ and bond distances $\left({ }^{\circ}\right)$ : $\mathrm{C} 1-\mathrm{N} 1=1.323(4) \AA, \mathrm{C} 1-\mathrm{N} 2=$ $1.332(4), \mathrm{C} 2-\mathrm{N} 1=1.373(4), \mathrm{C} 4-\mathrm{N} 1=1.477(5) ; \mathrm{N} 1-$ $\mathrm{C} 1-\mathrm{N} 2=108.0(3), \mathrm{C} 1-\mathrm{N} 1-\mathrm{C} 2=108.6(3), \mathrm{C} 3-\mathrm{N} 2-\mathrm{C} 5=$ $124.5(3)$.

\section{$2.4 X$-ray structure determination of 1}

Diffraction data for $\mathbf{1}$ was obtained on a Rigaku Saturn $724+$ (4 x 4 bin mode) diffractometer equipped with a rotating anode using Mo $\mathrm{K} a$ radiation $(\lambda=$ $0.7107 \AA$ ). The diffraction data were measured at $293 \mathrm{~K}$ in the range $3.30<2 \theta<24.99$. Structure solution and refinement were achieved with standard Patterson and Fourier techniques. All non-hydrogen atoms were refined with anisotropic displacement parameters. Hydrogen atoms were added to the structure models at calculated positions.

\section{Selected crystallographic details for 1}

Mol. Formula $=\mathrm{C}_{18} \mathrm{H}_{20} \mathrm{Br}_{2} \mathrm{~N}_{6}$, Colourless crystals, $M=480.22$, Tetragonal, space group $\mathrm{P}_{3} 2_{1} 2, \mathrm{a}=$ 11.969(3), $\mathrm{b}=11.969(3), \mathrm{c}=14.415(4) \AA, a=\beta=$ $\gamma=90^{\circ}, V=2065.05 \AA^{3}, Z=4, \mathrm{Dc}=1.544 \mathrm{~g} \mathrm{~cm}^{-3}$, $\mu(\mathrm{Mo} \mathrm{K} \alpha)=3.939 \mathrm{~mm}^{-1}, \mathrm{~F}(000)=960, \mathrm{~T}=293 \mathrm{~K}$, $\mathrm{GoF}=0.98$, final $R_{1}=0.0282$ and $\mathrm{w} R_{2}=0.0642$ for $I>2 \sigma(I), R_{1}=0.0707, \mathrm{w} R_{2}=0.0965$ for all data. CCDC Number: 1035187.

\section{Results and Discussion}

The reaction of 2,3-bis(bromomethyl)quinoxaline with two equivalents of 1-methyl imidazole in acetonitrile under reflux conditions afforded 2,3 bis-(imidazolylmethyl)quinoxaline (1) as brown colour solid (scheme 1). The crude product was purified by recrystallization from ethanol to get colourless crystals in $75 \%$ yield. ${ }^{13}$ The

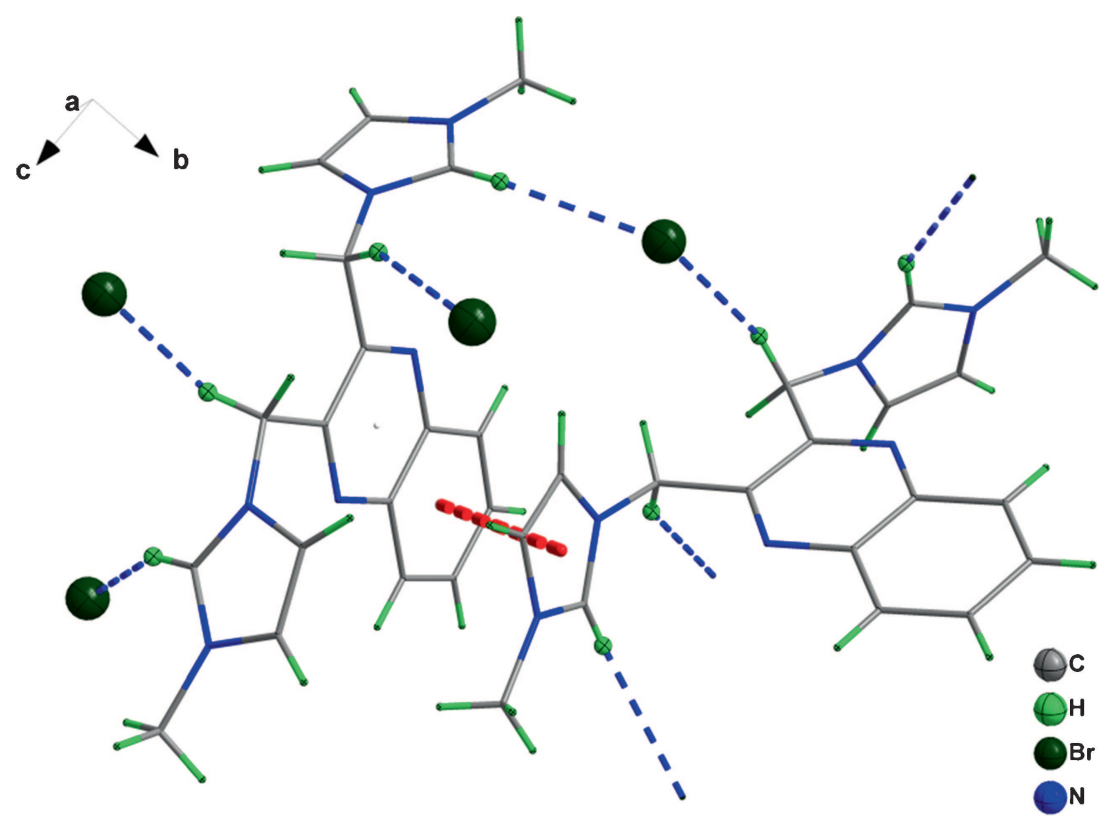

Figure 2. Intermolecular hydrogen bonding $(2.71 \AA)$ and $\pi-\pi$ stacking (3.69 $\AA$ ) interactions leading to polymeric structure in the crystal lattice of $\mathbf{1}$. 


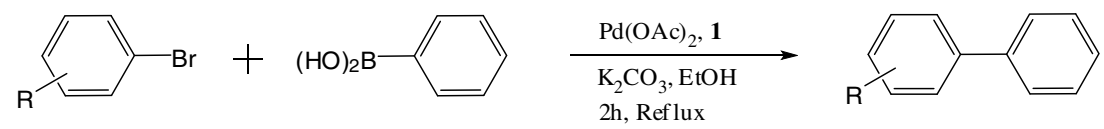

Scheme 2. Suzuki-Miyaura cross-coupling reaction.

Table 1. Suzuki-Miyaura reaction of phenylboronic acid with aryl halides.

Entry

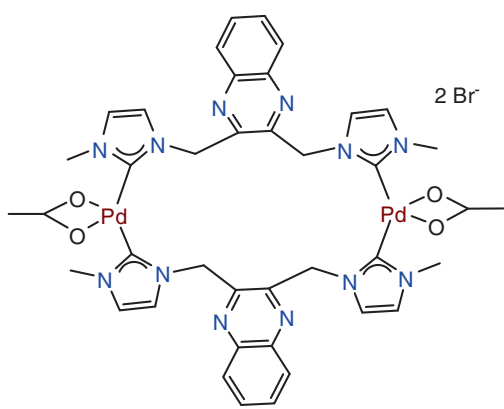

VII

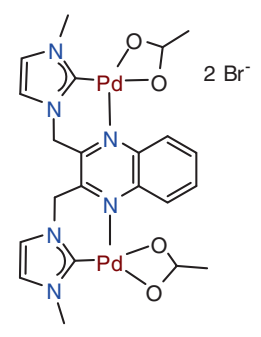

VIII
Figure 3. Proposed structures for complexes VII and VIII.

${ }^{1} \mathrm{H}$ NMR spectrum of the diimidazolium salt $\mathbf{1}$ showed the signal for NCHN protons at $9.42 \mathrm{ppm}$, which is in the range of NCHN protons of imidazolium and benzoimidazolium salts. The resonances for N-Methyl and methylene protons appear as singlets at $4.00 \mathrm{ppm}$ and $6.17 \mathrm{ppm}$, respectively (figure 1).

The compound $\mathbf{1}$ crystallizes in tetragonal crystal system with $P 4_{3} 2_{1} 2$ space group. The two imidazolyl rings are almost perpendicular to the plane of the quinoxaline ring. The carbene carbon (NCHN) of both the imidazolyl groups are aligned in opposite direction to each other as observed in pyrazine based diimidazolium salts. The C1-N1 [1.323(4) $\AA]$ and C1-N2 [1.332(4) $\AA$ ] bond distances as well as the N1-C1-N2 bond angle $\left[108.0(3)^{\circ}\right]$ are comparable with the same observed in arene bridged diimidazolium salts. ${ }^{11}$

The crystal structure of $\mathbf{1}$ shows interesting $(\mathrm{C}-\mathrm{H})^{+} \ldots$ $\mathrm{Br}^{-}$ionic hydrogen bonding. The imidazolium moiety of the ligand is involved in hydrogen bonding with the bromide ion with the bromide ion with $\mathrm{C} 1-\mathrm{H} 1 \ldots$ $\mathrm{Br} 1=2.716 \AA$ and $\mathrm{C} 1-\mathrm{H} 1-\mathrm{Br} 1=150.2^{\circ}$. The bromide ion is further involved in hydrogen bonding with one of the hydrogen of the methylene group [C5-H5 .... $\left.\mathrm{Br} 1=2.839 \AA,<\mathrm{C} 5-\mathrm{H} 5 \cdots \mathrm{Br} 1=152.9^{\circ}\right]$. As both the imidazolyl groups are pointing in opposite directions, the H-bonding leads to the formation of a polymeric structure in the solid state. Furthermore, intermolecular $\pi-\pi$ stacking interaction is observed between one of the imidazoles and quinoxaline ring as shown in figure 2 (distance $=3.69 \AA$ ). 


\subsection{Suzuki-Miyaura cross coupling reaction}

Attempts to isolate the Pd-complex of quinoxalineimidazolium salt by transmetallation method using $\mathrm{Ag}_{2} \mathrm{O}$ and by also direct deprotection method have been unsuccessful. Thus, a mixture of diimidazolium salt $\mathbf{1}$ and $\mathrm{Pd}(\mathrm{OAc})_{2}$ was employed as the catalytic system for Suzuki-Miyaura and Mizoroki-Heck coupling reactions. The Pd-catalyzed Suzuki-Miyaura coupling reaction of para-bromo benzaldehyde and other aryl bromides with phenyl boronic acid has been carried out (scheme 2). All the reactions were carried out under reflux conditions in air by using environmentally benign $\mathrm{EtOH}$ as solvent and $\mathrm{K}_{2} \mathrm{CO}_{3}$ as base. Chromatographic analysis of the reaction mixture revealed $96 \%$ conversion in $2 \mathrm{~h}$ under reflux conditions.

To expand the scope of catalytic investigation, several meta and para substituted aryl bromides with phenyl boronic acid as the coupling partner were employed under the given reaction conditions. Good to excellent conversions were observed for the desired biphenyl product with conversion ranging from 80-93\% (table 1, entry 2-6). Moderate to good conversions were also observed for heteroaromatic bromides such as 2-bromo pyridine and 2-bromo thiophene (table 1, entry 7-8). Homo-coupling product was not observed in all the cases. The in situ generated catalyst in this cross-coupling reaction is proposed to be VII (figure 3), a dimeric complex where two Pd centres are bridging between two imidazolyl-carbene ligands, as observed in the case of benzmidazolium derivative. ${ }^{14}$

\subsection{Mizoroki-Heck cross-coupling reaction}

Heck coupling reactions were carried out with a 1:2 mixture of diimidazolium salt $\mathbf{1}$ and palladium acetate as catalyst precursor by choosing 4-bromo benzaldehyde and styrene as the cross-coupling partners (scheme 3). Under the optimized conditions (1.0 mol\% of diimidazolium salt $1,2.0 \mathrm{~mol} \%$ of $\left[\mathrm{Pd}(\mathrm{OAc})_{2}\right]$ and $2.0 \mathrm{mmol}$ of $\mathrm{K}_{2} \mathrm{CO}_{3}$ in dimethylformamide at $130^{\circ} \mathrm{C}$ over a reaction period of $24 \mathrm{~h}$, almost quantitative conversions were achieved. Electron withdrawing aryl bromides showed better conversions. However moderate conversions were obtained with electron donating aryl halides. In all the cases moderate to good selectivity towards the trans product was observed (table 2). The in situ generated catalyst in the Heck cross-coupling reaction is proposed to be VIII (figure 3), where the $\mathrm{Pd}$ centres are coordinated to $(\mathrm{C}, \mathrm{N})$ hetero-donor carbene ligand. The metal centres in this case are in remote positions which can be seen as the dinuclear version of the picoline or benzoimidazoline functionalized carbene complexes.

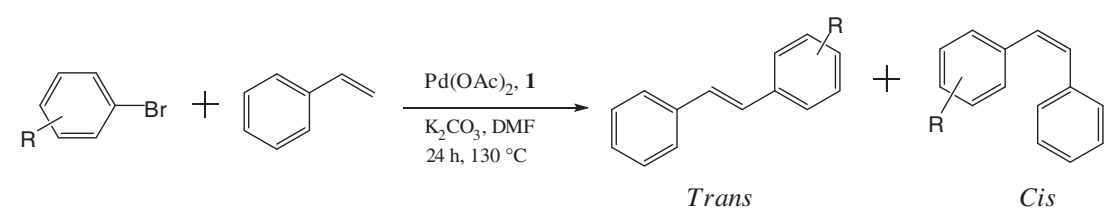

Scheme 3. Mizoroki-Heck cross-coupling reaction.

Table 2. Mizoroki-Heck reaction of styrene with various aryl halides.

Entry


The catalytic activity in Suzuki-Miyaura cross coupling reactions is moderate in comparison to Pd-phosphine based ligand systems. ${ }^{12 \mathrm{~b}, \mathrm{c}}$ The catalytic activity for the Heck cross-coupling reaction is lower than those found for well-defined palladium complexes with mixed carbene/phosphine, pincer-type ligands which exhibit better conversion rates for shorter reaction times, even with low catalyst loading. ${ }^{15}$

\section{Conclusions}

We have demonstrated the use of in situ prepared palladium catalyst with quinoxaline bridged diimidazolium salt (1) in Suzuki as well as Heck cross-coupling reactions. This is a versatile catalytic system which effectively catalyses Suzuki cross-coupling reactions at ambient conditions for a wide range of substrates using environmentally benign ethanol as solvent. Moderate to good selectivity towards the trans-product was observed in Mizoroki-Heck reactions. The coordination chemistry and further exploration of the catalytic activity of diimidazolium salt is under active investigation.

\section{Supplementary Information}

${ }^{1} \mathrm{H},{ }^{13} \mathrm{C}$ NMR and ESI-MS Spectral data for $\mathbf{1}$ are provided. The electronic supplementary information can be seen at www.ias.ac.in/chemsci. Crystallographic data for 1 has been deposited at the Cambridge Crystallographic Data Centre with CCDC no. 1035187. This data can be obtained free of charge at www.ccdc.cam.ac.ul/conts/ retrieving.html [or from the Cambridge Crystallographic Data Centre (CCDC), 12 Union Road, Cambridge CB2 1EZ, UK; fax: +44(0)1223-336033; E-mail: deposit@ ccdc.cam.ac.uk +44(0)1223-3360].

\section{Acknowledgements}

We are grateful to the Science \& Engineering Research Board, New Delhi, India for financial support of this work through grant No. SB/S1/IC-08/2014. MMS thanks the Council of Scientific Industrial Research (CSIR), New Delhi, for Senior Research Fellowship (SRF).

\section{References}

1. (a) Negishi E 2002 In Handbook of Organopalladium Chemistry for Organic Synthesis Vol. 1 E I Negishi (Ed.) (New York: Wiley Interscience) p. 1133; (b) Wu X-F, Neumann H and Beller M 2013 Chem. Rev. 1131
2. (a) Magano J and Dunetz J R 2011 Chem. Rev. 111 2177; (b) Miyaura N and Suzuki A 1995 Chem. Rev. 95 2457

3. Miyaura N, Yanagi T and Suzuki A 1981 Synth. Commun. 11513

4. (a) Slagt M Q, van Zwieten D A P, Moerkerk A J C M, Klein Gebbink R J M and van Koten G 2004 Coord. Chem. Rev. 248 2275; (b) Takenaka Z, Minakawa M and Uozumi Y 2005 J. Am. Chem. Soc 127 12273; (c) Motoyama Y, Mikami Y, Kawakami H, Aoki K and Nishiyama H 1999 Organometallics 183584

5. Arduengo A J III, Harlow R L and Kline M 1991 J. Am. Chem. Soc. 113361

6. (a) Hahn F E and Jahnke M C 2008 Angew. Chem., Int. Ed. 47 3122; (b) Hahn F E 2006 Angew. Chem., Int. Ed. 45 1348; (c) Bourissou D, Guerret O, Gabbai F P and Bertrand G 2000 Chem. Rev. 10039

7. (a) Hahn F E, Jahnke M C and Pape T 2006 Organometallics 26 150; (b) Peris E, Loch J A, Mata J and Crabtree R H 2001 Chem. Commun. 201; (c) Hahn F E, Jahnke M C, Gomez-Benitez V, Morales-Morales D and Pape T 2005 Organometallics 24 6458; (d) del Pozo C, Iglesias M and SaÌnchez F 2011 Organometallics 30 2180; (e) Liu X and Braunstein P 2013 Inorg. Chem. 52 7367; (f) Lee H M, Zeng J Y, Hu C-H and Lee M-T 2004 Inorg. Chem. 436822

8. (a) Lee K-M, Chen J C C and Lin I B J $2001 \mathrm{~J}$. Organomet. Chem. 364 617; (b) Scheele U J, Dechert S and Meyer F 2006 Inorg. Chim. Acta 3594891

9. Albert K, Gisdakis P and Rosch N 1998 Organometallics 171608

10. (a) Kantchev E A B, O'Brien C J and Organ M G 2007 Angew. Chem., Int. Ed. 46 2768; (b) Normand A T and Cavell K J 2008 Eur. J. Inorg. Chem. 2781

11. (a) Tulloch A A D, Danopoulos A A, Tooze R P, Cafferkey S M, Kleinhenz S and Hursthouse M B 2000 Chem. Commun. 1247; (b) Tulloch A A D, Danopoulos A A, Kleinhenz S, Light M E, Hursthouse M B and Eastham G 2001 Organometallics 20 2027; (c) Jahnke M C, Hussain M, Hupka F, Pape T, Ali S, Hahn F E and Cavell K J 2009 Tetrahedron 65909

12. (a) Ganeshamoorthy C, Mague J T and Balakrishna M S 2008 Eur. J. Inorg. Chem. 596; (b) Punji B, Mague J T and Balakrishna M S 2007 Inorg. Chem. 46 11316; (c) Punji B, Mague J T and Balakrishna M S 2007 Inorg. Chem. 46 10268; (d) Rao S, Mague J T and Balakrishna M S 2013 Dalton Trans. 42 11695; (e) Ibrahim S M, Ganeshamoorthy C and Balakrishna M S 2013 Ind. J. Chem. 52A 1400; (f) Mohanty S, Suresh D, Balakrishna M S and Mague J T 2009 J. Organomet. Chem. 6942114

13. Singh J N, Jun J E, Chellappan K, Thangadirai D, Chandran P R, Hwang I C, Yoon J and Kim S K 2007 Org. Lett. 9485

14. Liu Q-X, Yao Z-Q, Zhao X-J, Zhao Z-X and Wang X G 2013 Organometallics 323493

15. (a) Andrus M B, Song C and Zhang J 2002 Org. Lett. 4 2079; (b) Wheaton C A, Bow J-P J and Stradiotto M 2013 Organometallics 32 6148; (c) Luo Q, Eibauer S and Reiser O 2007 J. Mol. Catal A: Chem. 26865 